\title{
Structural Modelling of Multi-thread Fancy Yarn
}

DOI:

10.1108/ijcst-05-2017-0063

\section{Document Version}

Accepted author manuscript

Link to publication record in Manchester Research Explorer

\section{Citation for published version (APA):}

Alshukur, M., \& Gong, R. (2018). Structural Modelling of Multi-thread Fancy Yarn. International journal of clothing science and technology. https://doi.org/10.1108/ijcst-05-2017-0063

\section{Published in:}

International journal of clothing science and technology

\section{Citing this paper}

Please note that where the full-text provided on Manchester Research Explorer is the Author Accepted Manuscript or Proof version this may differ from the final Published version. If citing, it is advised that you check and use the publisher's definitive version.

\section{General rights}

Copyright and moral rights for the publications made accessible in the Research Explorer are retained by the authors and/or other copyright owners and it is a condition of accessing publications that users recognise and abide by the legal requirements associated with these rights.

\section{Takedown policy}

If you believe that this document breaches copyright please refer to the University of Manchester's Takedown Procedures [http://man.ac.uk/04Y6Bo] or contact uml.scholarlycommunications@manchester.ac.uk providing relevant details, so we can investigate your claim.

\section{OPEN ACCESS}




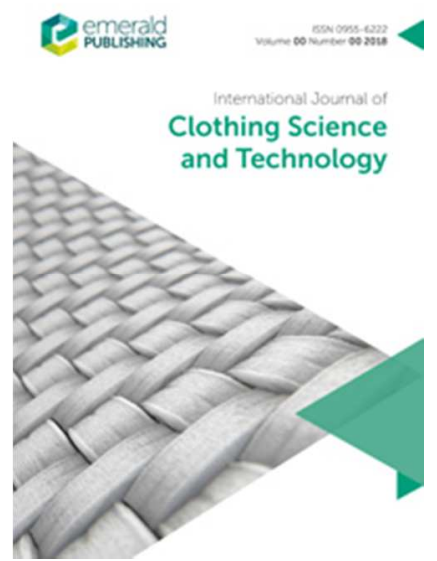

\section{Structural Modelling of Multi-thread Fancy Yarn}

\begin{tabular}{|r|l|}
\hline Journal: & International Journal of Clothing Science and Technology \\
\hline Manuscript ID & IJCST-05-2017-0063 \\
\hline Manuscript Type: & Research Paper \\
\hline Keywords: & fancy yarn, structural modelling, mathematical modelling, yarn geometry \\
\hline \multicolumn{2}{|c}{} \\
\hline
\end{tabular}

SCHOLARONE $^{\text {"M }}$

Manuscripts 


\section{Abstract}

Purpose: The structure of doubled fancy yarns made by combining together several threads has been modelled mathematically in this article.

Design/methodology/approach: It was assumed that such a structure may have two distinctive parts- sinusoidal and helical (i.e. sigmoidal). This model is based on calculating the length of the effect thread in relation to the core thread. The case of having several variants of such a structure was discussed to account for several types of doubled fancy yarns. The number of wraps of the binder, the overfed ratio, and heights of the fancy profiles in the different parts were the fundamental parameters of this model. The effects of changes in the number of wraps, the overfeed ratio or both simultaneously, on this model, were also considered. The Shape Factor of Fancy Yarn was also modelled depending on the basic model of the structure.

Findings: The model was tested and the correlation coefficient between the theoretical value and the real value of length of the effect thread was 0.90 .

Originality/value: This model is useful for predicting the length of the effect component based on the type, dimension and number of the fancy profiles of doubled fancy yarn, and for understanding the changes of the multiple-thread structure of fancy yarn when the overfeed ratio and /or the number of wraps were to change.

Keywords: fancy yarn; structural modelling; mathematical modelling; yarn geometry 


\section{Introduction}

Fancy yarn was defined by as "special products of carding, drawing, Dref spinning, rotor spinning, twisting, texturing, etc. technologies with introduced visual irregular characteristics, in either diameter and unevenness or/and in colour" (Petrulyte, 2003). Research related to fancy yarns is conducted worldwide and one of its aspects is the assessment of yarn structure. For example, the methods suggested by (Alshukur, 2013a, Alshukur, 2013b) were used to measure the fancy projections depending on the Number of Fancy Profiles in a unit length of the ultimate fancy yarn, the Size of Fancy Profile, the Circularity Ratio of Fancy Profile (CR \%) and the Shape Factor of Fancy Yarn (ShF). Those methods were applied to gimp yarns, bouclé yarns and overfed fancy yarns made on hollow-spindle spinning machines (Alshukur and Fotheringham, 2014b). Other important aspects of research into fancy yarn are their structure and geometry, and factors affecting their properties (Alshukur and Fotheringham, 2014a, Alshukur and Fotheringham, 2014b).

Theoretical modelling of the fancy yarn structure has also grabbed the attention of researchers. One of the earliest theoretical models of fancy yarns made by means of twisting was reported by (Marton, 1987). Marton calculated the amount of twist remaining in the basic thread (the core) after being bound with the effect thread. Following this, the length of one fancy profile was calculated. Formulae to calculate the coil length of knop yarns having $m$ coil layers were constructed. Finally, a table was given to suggest values of the structural factors related to some types of fancy yarns, such as: bouclé, nub, knot, loop, flamé and spiral fancy yarns (Marton, 1987). Although Marton called it bouclé, the technology and the manufacturing process described in his research are suitable to make gimp rather than bouclé yarns. Perhaps Marton was confusing the structure of wavy or gimp yarn with that of bouclé yarn. Following this, 
the structural parameters and the geometry of slub yarns, bouclé yarns and puff yarns made from drafted fibres were modelled by (Testore and Minero, 1988). The aim of their research was to ensure the reproducibility of these yarns without resorting to the experience of workers, empirical methods or trials. In another research, the appearance and the geometry of soufflé yarn, ombré yarn and knop yarn made from drafted fibres were studied by (Testore and Guala, 1989). More recently, a mathematical model for the length of the binder of multi-thread fancy yarns made on hollow-spindle machines was introduced. The binder was wound spirally around the effect and the core yarns. The formula presented relates to diameters of the components, and both the rotational speed of the hollow spindle and the delivery speed of the output, i.e. the number of wraps. Experimental analysis was conducted to calculate values of standard deviation. It was found to be between -4.6 and $+14.7 \%$ (Petrulyte, 2003). This research was repeated but the equations suggested were different because the linear density of threads was used instead of diameter. Values of standard deviations obtained ranged between 6.4 and $+5.7 \%$ (Petrulyte and Petrulis, 2003).

The first attempt to model the structures of bouclé yarn, loop yarn, snarl yarn, marl yarn and spiral yarn mathematically was conducted by (Grabowska, 2008). The cycloid formula was used to model the bouclé yarn structure while the trochoid used to model the loop yarn structure. The formulae of this research were used to describe the location of a point on the effect thread within the fancy yarn structure rather than to account for the structural parameters of multi-thread fancy yarn. The reason for this was the nature of Grabowoska's research; she aimed at modelling the strength of such fancy yarns, therefore, her formulae followed a method suitable for such an aim.

A simple structural model for fancy yarns which have multi-thread structure made by doubling, twisting or wrapping is not yet available. Such a model will be 
valuable for understanding doubled fancy yarns and other types of multi-thread fancy yarns. It can also be used to predict the structure and visual appearance of fancy yarn after being modified by changing the overfeed ratio or the number of wraps. This article describes a simple structural model which has a small number of parameters to make it easier to apply in industry and in academia.

\section{Assumptions}

The geometrical model of multi-thread fancy yarn of this work covers several types of fancy yarns, such as bouclé, semi-bouclé, gimp, wavy, overfed fancy yarn, and their commercial variants. The fancy yarn is considered to have at least three componentsthe core thread, the binder thread and the effect thread; although it is possible to extend this model to account for multi-thread fancy yarns made with two or three effect threads. In developing the model it is assumed that:

(1) Each of the components has a circular cross-section.

(2) The bending stiffness of the effect thread is uniformly distributed along the effect thread axis. Therefore, the effect thread bends in a uniform curvature.

(3) The radius of circular cross-section of each of the components is constant.

(4) The density and the packing density of the fibres are uniform and constant along each thread axis.

(5) The threads are neither extensible nor compressible.

(6) The core thread is always straight. Applying a suitable level of tension on this component while manufacturing the fancy yarn may secure such an assumption. This assumption is needed to make the model simple; otherwise, the core thread would assume a helical configuration. 
(7) The bouclé yarn may have more than one type of fancy profiles, in particular bouclé projections and sigmoidal sections.

The basic building unit of the structure of multi-thread fancy yarn may be modelled visually, as shown in Figure 1. This unit is assumed to repeat regularly along the fancy yarn length. Taken into account the schematic diagram in Figure 1, it is observed that this multi-thread fancy yarn has two parts:

- Part 1: a sinusoidal part, which is formed by the bouclé profiles, and it may extend over $m$ sections. Though, it is only visualised in Figure 1 to extend over 2 sections.

- Part 2: a helical part, which is the sigmoidal part of the fancy yarn, and it may extend over $n$ sections. Figure 1 shows that the helical part has extended over 4 sections, though.

----- please insert Figure 1 here -----

Firstly, the helical part forms as a helix within the spinning zone on the machine, then it slightly deforms locally by the pressure of the binder (helix) at the points of contact. Such a local alteration in the helical part configuration may not affect the accuracy of the model because the length of the helix itself does not change, neither its diameter at the middle between the contact points. Such a minor alteration accounts for obtaining the sigmoidal sections of multi-thread fancy yarn. A precise account of such a minor deformation renders the model over-complicated, thus it may lose its practical importance. 


\section{Model Development}

To develop a mathematical model of the whole fancy yarn, it is possible to model its two parts first, then combining the resulting models. The objective is to build up models for the length of the effect thread and the overfeed ratio for both parts of the structure proposed. The independent variables are the number of wraps of the binder (W), the height of the fancy projections and the length of the core thread.

\subsection{Part 1: Sinusoidal Part}

This Part is depicted in Figure 2. Suppose the sinusoidal function representing this part starts from the origin of a co-ordinate system, and the core thread axis coincide with the $\mathrm{x}$ axis. The sinusoidal function (i.e. representing a sine wave) may be given by the formula:

$$
y=A \sin \left(\frac{2 \pi x}{L_{1}}\right)
$$

Where $\mathrm{A}$ is the amplitude of a sine wave in its general form and $\mathrm{L}_{1}$ is the length of the core thread in the sinusoidal part of the model.

Suppose $\mathrm{L}_{1}=\mathrm{L}_{2}$ is the length of one segment of the fancy yarn; each segment may correspond to one turn of the binder; thus, a segment may have two sections. The sections are determined between the contact points of the core, the binder and the effect thread. Let $\mathrm{H}_{1}$ represents the height of the sinusoidal part of the effect thread, then $\mathrm{A}=$ $H_{1}$. The length of the effect thread of this part $\left(L_{e 1}\right)$ is the length of a sine wave function. Integrating this function over $x$ may give the length of the sine wave. The integration required to calculate the length between two definite, boundaries values $c$ and $d$ of $x$ is: 


$$
L_{e 1}=\int_{c}^{d} \sqrt{1+\left(\frac{d y}{d x}\right)^{2}} d x
$$

----- please insert Figure 2 here -----

The derivative of y over $x$ is:

$$
\frac{d y}{d x}=A \frac{2 \pi}{L_{1}} \cos \left(\frac{2 \pi x}{L_{1}}\right)
$$

To make the calculus simpler, Let $B=\frac{2 \pi}{L_{1}}$.Therefore, the integration given in equation (2) was calculated the formula ${ }^{1}$ :

$$
\int \sqrt{1+A^{2} B^{2} \cos ^{2}(B x)} d x=\frac{\sqrt{A^{2} B^{2} \cos (2 B x)+A^{2} B^{2}+2} E\left(B x, \frac{A^{2} B^{2}}{A^{2} B^{2}+1}\right)}{B \sqrt{\frac{A^{2} B^{2} \cos (2 B x)+A^{2} B^{2}+2}{A^{2} B^{2}+1}}}+\text { constant }
$$

Where: $E(\Phi, \mathrm{k})$ is an incomplete elliptic integral of the second kind. $E$ is given by the formula:

$$
E(\Phi, k)=\int_{0}^{\phi} \sqrt{1-k^{2} \sin ^{2} \theta} d \phi
$$

Instead of integrating equation (5) to obtain a value for $E$, it is possible to estimate the value of $E$ numerically. The integration of formula (4) is calculated between the boundaries from $c=0$ to $d=\mathrm{L}_{1}$, thus:

$$
\left.L_{e 1}=\int_{0}^{L_{1}} \sqrt{1+\left(\frac{2 \pi H_{1}}{L_{1}}\right)^{2} \cos ^{2}\left(\frac{2 \pi x}{L_{1}}\right)} d x=\left[\frac{\sqrt{\frac{4 \pi^{2} H_{1}^{2}}{L_{1}^{2}} \cos \left(\frac{4 \pi x}{L_{1}}\right)+\frac{4 \pi^{2} H_{1}^{2}}{L_{1}^{2}}+2} E\left(\frac{2 \pi x}{L_{1}}, \frac{\frac{4 \pi^{2} H_{1}^{2}}{L_{1}^{2}}}{\frac{4 H_{1}^{2}}{L_{1}^{2}}+1}\right)}{\frac{\frac{2 \pi}{L_{1}}}{\sqrt{\frac{4 \pi^{2} H_{1}^{2}}{L_{1}^{2}} \cos \left(\frac{4 \pi x}{L_{1}}\right)+\frac{4 \pi^{2} H_{1}^{2}}{L_{1}^{2}}+2}}}\right]_{0}^{\frac{4 \pi^{2} H_{1}^{2}}{L_{1}^{2}}+1}\right]^{L_{1}}
$$


Since $E(0, x)=0, L_{e 1}$ became:

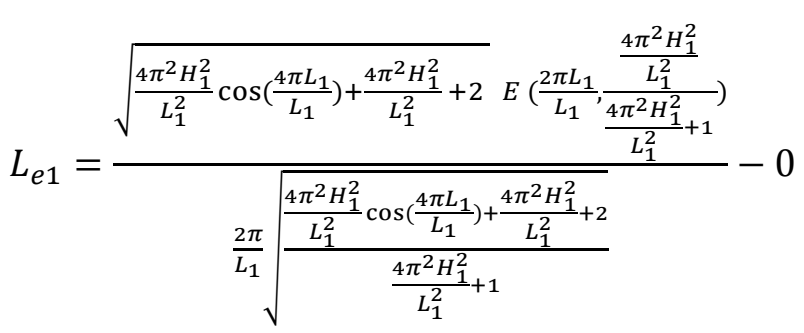

or

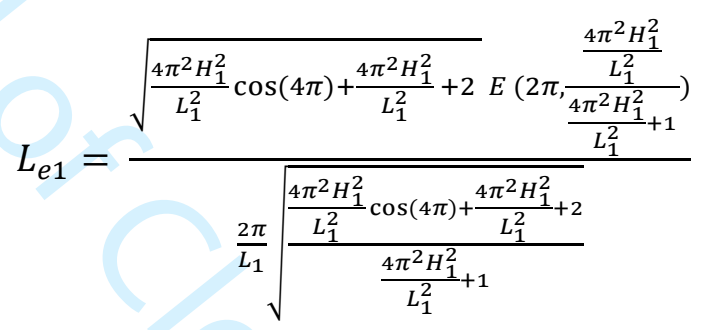

Since $\cos (4 \pi)=1$ and $L_{1}=\frac{1}{W}$, where $\mathrm{W}$ is the number of wraps of the binder, the previous formula becomes:

$$
L_{e 1}=\frac{\sqrt{4 \pi^{2} H_{1}^{2} W^{2}+4 \pi^{2} H_{1}^{2} W^{2}+2} E\left(2 \pi, \frac{4 \pi^{2} H_{1}^{2} W^{2}}{4 \pi^{2} H_{1}^{2} W^{2}+1}\right)}{2 \pi W \sqrt{\frac{4 \pi^{2} H_{1}^{2} W^{2}+4 \pi^{2} H_{1}^{2} W^{2}+2}{4 \pi^{2} H_{1}^{2} W^{2}+1}}}
$$

Further modifications make it:

$$
L_{e 1}=\frac{\sqrt{2\left(4 \pi^{2} H_{1}^{2} W^{2}+1\right)} E\left(2 \pi, \frac{4 \pi^{2} H_{1}^{2} W^{2}}{4 \pi^{2} H_{1}^{2} W^{2}+1}\right)}{2 \pi W \sqrt{2 \frac{\left(4 \pi^{2} H_{1}^{2} W^{2}+1\right)}{4 \pi^{2} H_{1}^{2} W^{2}+1}}}
$$

or

$$
L_{e 1}=\frac{\sqrt{2\left(4 \pi^{2} H_{1}^{2} W^{2}+1\right)} E\left(2 \pi, \frac{4 \pi^{2} H_{1}^{2} W^{2}}{4 \pi^{2} H_{1}^{2} W^{2}+1}\right)}{4 \sqrt{2} \pi W}
$$


Where Le1 is the length of only one sinusoidal section (i.e. one phase of the sine wave). However, because $\mathrm{L}_{\mathrm{e} 1}$ may usually extend over $m$ section of the sinusoidal part and not only two sections, the previous formula was modified to take the following form:

$$
L_{e 1}=\frac{m}{2} \frac{\sqrt{2\left(4 \pi^{2} H_{1}^{2} W^{2}+1\right)} E\left(2 \pi, \frac{4 \pi^{2} H_{1}^{2} W^{2}}{4 \pi^{2} H_{1}^{2} W^{2}+1}\right)}{2 \sqrt{2} \pi W}
$$

\subsection{Part 2: The Helical Part (i.e. Sigmoidal Part)}

Taken into account the schematic drawing in Figures 3 and 4, and depending on Pythagoras Theorem:

$$
L_{e 2}=\sqrt{L_{2}^{2}+4 \pi^{2} H_{2}^{2}}
$$

where $\mathrm{H}_{2}$ is the width of the helix.

$$
\text { ----- insert Figures } 3 \text { and } 4 \text { here ----- }
$$

Since it is assumed that the length of one section in the sinusoidal part and one section in the helical part of the yarn are equal, i.e. $L_{1}=L_{2}=\frac{1}{W}$, it is possible to write:

$$
L_{e 2}=\sqrt{\frac{1}{W^{2}}+4 \pi^{2} H_{2}^{2}}=\frac{\sqrt{1+W^{2} 4 \pi^{2} H_{2}^{2}}}{W}
$$

The length $\mathrm{L}_{\mathrm{e} 2}$ for only one helical section (that is half the length of a helix) is: 


$$
L_{e 2}=\frac{1}{2} \sqrt{\frac{1}{W^{2}}+4 \pi^{2} H_{2}^{2}}=\frac{\sqrt{1+4 \pi^{2} W^{2} H_{2}^{2}}}{2 W}
$$

Since $L_{e 2}$ may usually extends over more than only two fancy yarn sections, i.e. $n$ adjacent sections, the previous formula may thus be modified to take the form:

$$
L_{e 2}=\frac{n}{2} \sqrt{\frac{1}{W^{2}}+4 \pi^{2} H_{2}^{2}}=\frac{n}{2} \frac{\sqrt{1+4 \pi^{2} W^{2} H_{2}^{2}}}{W}
$$

The total length of the effect thread thus becomes: $L_{e}=L_{e 1}+L_{e 2}$ or

$$
L_{e}=\frac{m}{2} \frac{\sqrt{2\left(4 \pi^{2} H_{1}^{2} W^{2}+1\right)} E\left(2 \pi, \frac{4 \pi^{2} H_{1}^{2} W^{2}}{4 \pi^{2} H_{1}^{2} W^{2}+1}\right)}{2 \sqrt{2} \pi W}+\frac{n}{2} \sqrt{\frac{1}{W^{2}}+4 \pi^{2} H_{2}^{2}}
$$

The overfeed ratio is

$$
\eta=\frac{L_{e}}{L_{c}}
$$

However, if $L$ is the length of the fancy yarn which correspond to $L_{e}$ ( i.e. it is made by both the sinusoidal and the helical part), and $L_{c}$ is the length of the core thread which correspond to $\mathrm{L}_{\mathrm{e}}$. then

$$
L_{c}=L=L_{1}+L_{2}=\frac{m}{2 W}+\frac{n}{2 W}=\frac{\lambda}{2 W}
$$

So,

$$
\eta=\frac{\frac{m}{2} \frac{\sqrt{2\left(4 \pi^{2} H_{1}^{2} W^{2}+1\right)} E\left(2 \pi, \frac{4 \pi^{2} H_{1}^{2} W^{2}}{4 \pi^{2} H_{1}^{2} W^{2}+1}\right)}{2 \sqrt{2} \pi W}+\frac{n}{2} \sqrt{\frac{1}{W^{2}}+4 \pi^{2} H_{2}^{2}}}{\frac{\lambda}{2 w}}
$$

or 


$$
\eta=\frac{m}{2} \frac{\sqrt{2\left(4 \pi^{2} H_{1}^{2} W^{2}+1\right)} E\left(2 \pi, \frac{4 \pi^{2} H_{1}^{2} W^{2}}{4 \pi^{2} H_{1}^{2} W^{2}+1}\right)}{\sqrt{2} \pi \lambda}+\frac{n W}{\lambda} \sqrt{\frac{1}{W^{2}}+4 \pi^{2} H_{2}^{2}}
$$

\subsection{Special form of the model}

Depending on the technology used to make the multi-thread fancy yarn, the previous model may have a new form. For instance, when the hollow-spindle system is used, the sinusoidal section usually extends over one binder wrap, rather than half a wrap. This sinusoidal section is expected to be tilted rather than a flat projection. Similarly, the helical section also extends over a whole wrap, rather than half a wrap. Therefore, formulae 12, 16, 18 and 21 are modified respectively as follow:

$$
\begin{aligned}
& L_{e 1}=m \frac{\sqrt{2\left(4 \pi^{2} H_{1}^{2} W^{2}+1\right)} E\left(2 \pi, \frac{4 \pi^{2} H_{1}^{2} W^{2}}{4 \pi^{2} H_{1}^{2} W^{2}+1}\right)}{2 \sqrt{2} \pi W} \\
& L_{e 2}=n \sqrt{\frac{1}{W^{2}}+4 \pi^{2} H_{2}^{2}}=\frac{n}{W} \sqrt{1+W^{2} 4 \pi^{2} H_{2}^{2}} \\
& L_{e}=m \frac{\sqrt{2\left(4 \pi^{2} H_{1}^{2} W^{2}+1\right)} E\left(2 \pi, \frac{4 \pi^{2} H_{1}^{2} W^{2}}{4 \pi^{2} H_{1}^{2} W^{2}+1}\right)}{2 \sqrt{2} \pi} W \\
& \eta
\end{aligned}
$$

\subsection{Testing the model}

The technology used was the hollow-spindle system. Therefore, formulae 22, 23, 24 and 25 of the special case were used instead of the original formulae. The fancy yarns were 
made using different machine settings, materials and characteristics as given in Table 1. Doing so may prove the versatility of this model regardless of the material types or machine settings.

--- please insert Table 1 here - - -

The results of this procedure are given in Table 2. The correlation coefficient (r) was calculated for the theoretical values and the experimental values of $L_{e}$ and it was $r$ $=0.90$. This value of $\mathrm{r}$ was significant at a significance level $\alpha=0.01$ ( $p$-value of the ANOVA testing was 0.000).

--- please insert Table 2 here - - -

The difference between the experimental values and the expected values (using the model) can be caused by several reasons. These may include the helical configuration of the core thread which was assumed to be straight in the model, the variation in the manufacturing process, and random variation. In all cases, the value of $r$ was high, which shows the applicability of this model. Therefore, based on the formulae of this model, it is possible to predict the length of the effect thread and the overfeed ratio necessary to make a particular multi-thread fancy yarn if the technology required to make it is already known. It is only required to analyse the structure of the fancy yarn by counting the number of the effect profiles, take their dimensions, then using the model to get a significant estimation of the length of the effect thread and the overfeed ratio required to make such a fancy yarn. 


\section{Discussions}

The model for the structure of multi-thread fancy yarn may have $m$ bouclé profiles and $n$ helical profiles, and the total number of sections is $\lambda=m+n$. Several different variants of the structure having $m$ number of bouclé profiles are possible, and the previous calculations and formulae may remain valid. Each wrap of the binder makes two sections of the fancy yarn. The sections $m$ and $n$ may be variables, and, accordingly, they define the resultant type of multi-thread fancy yarn. Examples of these alternative forms are given in Figure 5. The possibilities are given mathematically in a combination formula $\mathrm{C}(\lambda, m)$ as follows:

$$
C(\lambda, m)=\frac{\lambda !}{m !(\lambda-m) !}=\frac{\lambda !}{m ! n !}
$$

For example, if $\lambda=6$ and $m=2$, then the number of possibilities are:

$C(6,2)=\frac{6 !}{2 !(6-2) !}=\frac{6 !}{2 ! 4 !}=15$ variants of the previous structure, where, for instance $4 !=4 \times 3 \times 2 \times 1=24$.

With the notion that a combination in mathematics is a way of selecting several things (e.g. the two sinusoidal sections in the case of this model) out of a larger group (e.g. the total number of the proposed structure sections, i.e. 6 in Figure 1). Order of results is not important in the case of combination. Whether the positive or the negative element of the sinusoidal wave (i.e. part) appears in section one of the fancy yarn structure, the structure remains, or still considered to be, the same. What becomes different is the way one may look at the structure, i.e. from above or from below. If the order is thought to be important, then permutation (which is a statistical concept to estimate probability) must be used. 
----- please insert Figure 5 here -----

\subsection{Types of fancy yarn represented by the structural model}

With reference to the diagram in Figure 1 and the formulae for $\mathrm{L}_{\mathrm{e}}$, there are eight cases to be considered:

(1) When $\lambda=m ; n=0$, the structure has only sinusoid sections and the fancy yarn is a pure bouclé yarn.

(2) When $m>>n$, the fancy yarn may be recognized as a bouclé yarn.

(3) When $m \geq n$, the fancy yarn may be recognized as a semi-bouclé yarn.

(4) When $m<n$, the fancy yarn may be called an overfed fancy yarn.

(5) When $m<<n$, the fancy yarn may be called a gimp yarn derivative.

(6) When $m=0 ; \mathrm{H}_{2}=\mathrm{R}_{\mathrm{c}}+\mathrm{R}_{\mathrm{e}}$ the fancy yarn is a spiral yarn.

(7) When $m=0 ; \mathrm{H}_{2}>\mathrm{R}_{\mathrm{c}}+\mathrm{R}_{\mathrm{e}}$ and $\mathrm{H}_{2}>1 / 2 \mathrm{~L}_{2}$ the fancy yarn is a gimp yarn.

(8) When $m=0 ; \mathrm{H}_{2}>\mathrm{R}_{\mathrm{c}}+\mathrm{R}_{\mathrm{e}}$ and $\mathrm{H}_{2}<1 / 2 \mathrm{~L}_{2}$ the fancy yarn is wavy yarn.

Where $R_{c}$ and $R_{e}$ are radii of the core thread and the effect thread respectively.

\subsection{Relationship between $\mathrm{n}$ and $\mathrm{m}$ and between $\mathrm{H}_{1}$ and $\mathrm{H}_{2}$ :}

Since $\lambda=n+m$, if $\lambda$ is made constant, an increase in $m$ means a reduction in $n$, and vice versa. Further, heights $\mathrm{H}_{1}$ and $\mathrm{H}_{2}$ are inversely related for a specific length of the effect thread $\mathrm{L}_{\mathrm{e}}$. An increase in the former leads to a reduction in the latter, and vice versa. 


\subsection{The effect of changing the overfeed ratio ( $\eta)$}

Considering formula 18 , there are several scenarios. In the first scenario, suppose $\mathrm{L}_{\mathrm{c}}, \mathrm{W}$, $m$ and $n$ were all made constant, an increase in one of, or both, $\mathrm{H}_{1}$ and $\mathrm{H}_{2}$ may lead to an increase in $L_{e}$, and vice versa. If $\eta$ increases, $L_{e}$ must increase. Therefore, depending on the previous preconditions, $\mathrm{H}_{1}$ and $\mathrm{H}_{2}$ should increase accordingly. Consequently, the average size of the fancy projection should increase. In the second scenario, one may expect the height of the sinusoid to remain constant, i.e. $\mathrm{H}_{1}=$ const. In this case, an increase in $\mathrm{L}_{\mathrm{e}}$ may result in an increase in the width of the helical sections $\left(\mathrm{H}_{2}\right)$ and they may appear bulkier on the final fancy yarn. If $\mathrm{H}_{2}$ increases sufficiently to become equal to $\mathrm{H}_{1}$, the whole helical sections of the fancy yarn may become approximately similar to the bouclé sections after being deformed by the binder. This means that the number of bouclé and semi-bouclé projections increases. Further, during manufacturing of the fancy yarn, the increase in either $\mathrm{H}_{1}$ or $\mathrm{H}_{2}$ may not be regular. One may expect the height of the helical sections which are adjacent to the sinusoidal sections to increase. However, it may not reach the already greater height of such sinusoidal sections. So, the variation in height increases.

The last two scenarios may happen in practice for practical reasons related to the technology used to make the multi-thread fancy yarn. For example, considering hollowspindle spinning machines, the main constraints are the number of wraps of the binder, the limitation of space available for the bent effect thread (because of the balloon of the binder during unwinding it off the hollow-spindle), and the variability of stiffness of the effect thread. Unless the effect thread is unnecessarily stiff, those constraints do not allow excessive heights of the sinusoidal waves to form. The changes in the height $\Delta H_{1}$ is expected to be relatively small. However, to increase the overfeed ratio, there must be an increase in the length of the effect thread, i.e. $\Delta \mathrm{L}_{\mathrm{e}}$. Therefore, and based on the 
constraints stated above, there is a chance to increase $H_{2}$ more than $H_{1}$, i.e. $\Delta H_{2}>\Delta H_{1}$. Such a prediction can happen in practice locally in some sections rather than over the whole helical parts. Subsequently, more semi-bouclé projections are formed but with shapes that are not exactly resembling the sine waves. The height of such new semibouclé projections might not reach $H_{1}$. Therefore, it can be stated that if $\lambda=$ const and $\Delta \eta$ $>0$, then $\Delta m>0, \Delta n<0$ where $m, n$ remains positive numbers. These conclusions may be inferred mathematically from formula 16 as follows. The length $L_{e 2}=$ $\frac{n}{2} \frac{\sqrt{1+4 \pi^{2} W^{2} H_{2}^{2}}}{W}$ may be rewritten as:

$$
\begin{gathered}
n=\lambda-m=\frac{2 W L_{e 2}}{\sqrt{1+4 \pi^{2} W^{2} H_{2}^{2}}} \\
m=\lambda-\frac{2 W L_{e 2}}{\sqrt{1+4 \pi^{2} W^{2} H_{2}^{2}}}
\end{gathered}
$$

Suppose $\mathrm{L}_{c}, \mathrm{~W}, \mathrm{H}_{1}$ are fixed, then $\lambda$ and $\mathrm{L}_{\mathrm{e} 1}$ do not change. If $\eta$ increases $\mathrm{L}_{\mathrm{e} 2}$ must also increase. Consequently the second term of formula 28 becomes smaller that its current value, thus $m$ increases in value. Additionally, $m$ also becomes higher in value if $\mathrm{H}_{2}$ of the sigmoid sections increases to become approximately close in value to $\mathrm{H}_{1}$. This case accounts for semi-bouclé sections. If $m$ increases $n$ must decreases.

\subsection{The effect of changing the number of wraps $(W)$}

Suppose $\eta$ is fixed while $\mathrm{W}$ changes but without affecting $\mathrm{H}_{2}$. Further, recalling that the length any sections of the ultimate fancy yarn $L_{1}=L_{2}=\frac{1}{W}$; thus, an increase in the number of wraps $\mathrm{W}$ may reduce $\mathrm{L}_{1}$. Besides that, from formula 16, an increase in $\mathrm{W}$ may reduce the length $\mathrm{L}_{\mathrm{e} 2}$ of one helical section. Taking into considerations that in all 
types of helix: $\mathrm{L}_{\mathrm{e} 2}>\mathrm{H}_{2}$; thus, the numerator in formula 27 is always greater in value than the denominator. Therefore, a change in the former is always greater than the change in the latter. Consequently, $n$ increases in value when $\mathrm{W}$ increases (i.e. if $\Delta \mathrm{W}>$ 0 , then $\Delta n>0$ ). Furthermore, regarding the sinusoidal parts, suppose $\mathrm{H}_{1}$ is fixed and suppose the elliptical integration of the second kind, in formula 12, equals to $\psi$ :

$$
\psi=E\left(2 \pi, \frac{4 \pi^{2} H_{1}^{2} W^{2}}{4 \pi^{2} H_{1}^{2} W^{2}+1}\right)
$$

The value of this term can be estimated numerically when values of $\mathrm{W}$ and $\mathrm{H}_{1}$ are available. However, to understand how it changes when only $\mathrm{W}$ changes, it is possible to assume $4 \pi^{2} H_{1}^{2}=1$. Therefore,

$$
\psi=E\left(2 \pi, \frac{W^{2}}{W^{2}+1}\right)
$$

Considering the data of Table 3, it is found that when $\mathrm{W}$ increases, $\psi$ decreases.

$$
\text { --- please insert Table } 3 \text { here -- }
$$

$$
\begin{aligned}
& \text { Regarding the other part of formula } 12 \text {, it is assumed that: } \\
& \qquad \mathcal{F}=\frac{\sqrt{2\left(4 \pi^{2} H_{1}^{2} W^{2}+1\right)}}{2 \sqrt{2} \pi W}
\end{aligned}
$$

Where $\mathcal{F}$ can also be estimated numerically. Table 3 shows that when $\mathrm{W}$ increases, $\mathcal{F}$ decreases. Eventually, when $\mathrm{W}$ increases, the length $\mathrm{L}_{\mathrm{e} 1}$ must decrease. If the height of such sinusoidal sections remains unchanged, but their length decreases, the width $\mathrm{L}_{1}$ of their bases must decrease. This means that their area must decrease. From formula 28, 
when $\mathrm{W}$ increases without changing the height of the helical sections, $m$ decreases in value only if $\lambda$ remains unchanged. In reality, however, the height $\mathrm{H}_{2}$ of the already available helical or sigmoidal sections and the newly formed ones may increase slightly. Since each wrap of the binder makes two sections, i.e. if $\mathrm{W}=1$ thus $\lambda=2$. Therefore, $\mathrm{a}$ change in $\lambda$ is twice any change in W, i.e. $\Delta \lambda=2 \Delta \mathrm{W}$. For this, Formula 28 can be rewritten as:

$$
\Delta m=2 \Delta W-\frac{2 \Delta W L_{e 2}}{\sqrt{1+4 \pi^{2} \Delta W^{2} \Delta H_{2}^{2}}}
$$

The term $\frac{L_{e 2}}{\sqrt{1+4 \pi^{2} \Delta W^{2} \Delta H_{2}^{2}}}$ must be $\approx 1$ to get $\Delta m \approx 0$. Therefore, the new length of the helical effect thread in one section of the fancy yarn must be approximately:

$$
L_{e 2} \approx \sqrt{1+4 \pi^{2} \Delta W^{2} \Delta H_{2}^{2}}
$$

\subsection{Further Theoretical Advantages of the Model}

Based on the formulae of this modelling approach, it is possible to write a formula for the Shape Factor of Fancy (Bouclé) Yarn (ShF) which is introduced in (Alshukur, 2013a). Recalling that the $\mathrm{ShF}=m \times$ area under the length of the sinusoidal part $\mathrm{L}_{\mathrm{e}}$; thus:

$$
\begin{gathered}
\mathrm{ShF}=m \times \int_{0}^{L_{1} / 2} H_{1} \sin \left(\frac{2 \pi x}{L_{1}}\right) d x \\
\operatorname{ShF}=m H_{1}\left[-\frac{\mathrm{L}_{1}}{2 \pi} \cos \left(\frac{2 \pi x}{L_{1}}\right)\right]_{0}^{L_{1} / 2}=\frac{\mathrm{mH}_{1} \mathrm{~L}_{1}}{2 \pi}(-\cos \pi+\cos 0) \\
\mathrm{ShF}=\frac{\mathrm{mH}_{1} \mathrm{~L}_{1}}{2 \pi}
\end{gathered}
$$

If, however, the hollow-spindle system is used, half the sine wave will be representing 
the bouclé profile which extends over L1, and the equations of ShF become:

$$
\begin{gathered}
\mathrm{ShF}=m \times \int_{0}^{L_{1}} H_{1} \sin \left(\frac{2 \pi x}{2 L_{1}}\right) d x \\
\operatorname{ShF}=m H_{1}\left[-\frac{\mathrm{L}_{1}}{\pi} \cos \left(\frac{\pi x}{L_{1}}\right)\right]_{0}^{L_{1}}=\frac{\mathrm{mH}_{1} \mathrm{~L}_{1}}{\pi}(-\cos \pi+\cos 0) \\
\mathrm{ShF}=\frac{2 \mathrm{mH}_{1} \mathrm{~L}_{1}}{\pi}
\end{gathered}
$$

\subsection{Further Practical Advantages of the Model}

The implication of such a theoretical model in actual industrial situation are:

- to facilitate the manufacturing process of a copy of an already made fancy yarns if a previous knowledge about its manufacturing conditions is not available.

- to decide the type of multi-thread fancy yarn, after being made, based on the dimensions of its structures and components, i.e. $\mathrm{H}_{2}, \mathrm{R}_{\mathrm{c}}, \mathrm{R}_{\mathrm{e}}, m, n, \lambda, \mathrm{L}_{2}$.

- $\quad$ to predict the structure and the appearance of multi-thread fancy yarns after modifying the number of wraps or the overfeed ratio of the effect component.

However, when designing a new fancy yarn from the beginning, the model can be used by:

- defining the technology used to decide the type of formulae used, i.e. whether the general form or the special form;

- deciding the type of variant of fancy yarn to be made, i.e. bouclé, gimp, spiral, etc. 
- choosing an overfeed ratio suitable to make such a type of fancy yarn

- defining the number of wraps, to be used for the binder, taking into account the type of fancy yarn to be made and the overfeed ratio chosen. Information about these are given previously in an MPhil thesis (Alshukur, May 2012).

- deciding the machine settings and speeds of manufacturing;

- making the prototype of fancy yarn based on the previous conditions;

- testing the prototype to measure all its dimensions, in particular $\mathrm{H}_{2}, \mathrm{H}_{1}, \mathrm{R}_{\mathrm{c}}, \mathrm{R}_{\mathrm{e}}, m$, $n$;

- applying the formulae of the model to manipulate the overfeed ratio and the number of wraps in order to improve the prototype made to make a specific type of fancy yarn; and

- Once the structure has been improved as intended, it is possible to start the full production of that specific type of multi-thread fancy yarn.

\section{Conclusions}

This research is related to the mathematical modelling of structure of multi-thread fancy yarns by taking into account the length of the effect thread(s), the number of wraps and the overfeed ratio. Such a structure is first examined visually and regarded to have two parts- sinusoidal and helical. An incomplete elliptic integral of the second kind was used to calculate the length of the effect thread in the sinusoidal part, while simple trigonometry formulae were used to account for the helical sections of the effect thread. The model is universal for doubled fancy yarns, and it is simpler than previous versions 
reported in the literature. It is easy to apply in industry, to estimate the structure of a multi-thread fancy yarn, and in academia, for further development. The Shape Factor of Fancy (Bouclé) Yarn, which is used to assess the fancy bulkiness of bouclé yarn, was also modelled. This model account for several types of fancy yarn ranging from a "pure" bouclé yarn to bouclé yarn, semi-bouclé yarn, overfed fancy yarn, gimp yarn or its derivate, or even a spiral yarn. The geometrical model was tested and the correlation coefficient was 0.90 .

\section{Nomenclature}

$m \quad$ is the number of the sinusoidal sections

$\mathrm{n} \quad$ is the number of the helical sections

$\lambda=m+n \quad$ is the total number of sections in a basic building unit of the structure

$\mathrm{R}_{\mathrm{e}} \quad$ is the radius of the effect thread

$\mathrm{R}_{\mathrm{c}} \quad$ is the radius of the core thread

$\mathrm{H}_{1} \quad$ is the height of the helical sections

$\mathrm{H}_{2} \quad$ is the height of the sinusoidal sections

$\mathrm{L}_{1} \quad$ is the length of the core thread in the sinusoidal part corresponding to one sine wave

$\mathrm{L}_{2} \quad$ is the length of the core thread in the helical part corresponding to one helix

$\mathrm{L}_{\mathrm{c}}=\mathrm{L}_{1}+\mathrm{L}_{2} \quad$ is the length of the core thread corresponding to one building unit of the model

$L \quad$ is the length of the ultimate fancy bouclé yarn

W is the number of wraps of the binder 
$\mathrm{L}_{\mathrm{e} 1}$ is the length of the effect thread in the sinusoidal part corresponding to one sine wave

$\mathrm{L}_{\mathrm{e} 2}$ is the length of the effect thread in the helical part corresponding to one helix

$\mathrm{L}_{\mathrm{e}}=\mathrm{L}_{\mathrm{e} 1}+\mathrm{L}_{\mathrm{e} 2}$ is the length of the effect thread corresponding to the basic building unit

ShF is the Shape Factor of Fancy Yarn

SR is the Structural Ratio of Multi-thread Fancy Yarn

$\mathrm{E}(\Phi, \mathrm{k}) \quad$ is the incomplete elliptic integral of the second kind

$\eta=L_{e} / L_{c} \quad$ is the overfeed ratio, i.e $\eta \%=100\left(L_{e} / L_{c}\right)$

$\propto \quad$ is a symbol which denotes the positive relationship between two parameters

$\Delta \quad$ is used to refer for a change in a parameter

\section{End Notes}

1. The integrations of this article were completed online by using a website for mathematicians called Wolfram MathWorld, at www.wolframalpha.com, or mathworld.wolfram.com. 


\section{References}

ALSHUKUR, M. 2013a. The Quality of Fancy Yarn: Part I: Methods and Concepts. International Journal of Textile and Fashion Technology, 3, 11-24.

ALSHUKUR, M. 2013b. The Quality of Fancy Yarn: Part II: Practical Experiments and Application. International Journal of Textile and Fashion Technology, 3, 25-38.

ALSHUKUR, M. May 2012. Gimp Yarns: Structure, Properties, Quality and the Modelling of their Manufacturing Process on Hollow Spindle Spinning Machines. MPhil, Heriot-Watt University.

ALSHUKUR, M. \& FOTHERINGHAM, A. 2014a. Quality and structural properties of gimp fancy yarns by using the Design of Experiments. Journal of The Textile Institute, 106, 490-502.

ALSHUKUR, M. \& FOTHERINGHAM, A. 2014b. Role of false twist in the manufacturing process of multi-thread fancy yarn on hollow spindle spinning machines. Journal of The Textile Institute, 105, 42-51.

GRABOWSKA, K. E. 2008. A Mathematical Model of Fancy Yarns' Strength. The First Model Developed in the World. Fibres \& Textiles in Eastern Europe, 16, 9-14.

MARTON, E. 1987. Theoretical principles of fancy yarn twisting. Melliand English, E 242-243.

PETRULYTE, S. 2003. Complex Structure Fancy Yarns: Theoretical and Experimental Analysis. Materials Science, 9, 120-123.

PETRULYTE, S. \& PETRULIS, D. 2003. Forecasting of Structural Parameters of Hollow Spindle Yarns. Materials Science, 9, 293-296.

TESTORE, F. \& GUALA, G. M. 1989. Effect yarns: properties and parameters. Journal of The Textile Institute, 80, 377-390. 
TESTORE, F. \& MINERO, G. 1988. A Study of the Fundamental Parameters of Some Fancy Yarns. Journal of The Textile Institute, 4, 606-620. 


\section{List of Tables}

Table 1: Properties of Input Materials and Settings of the Hollow-spindle Machine that were Used to Make the Multi-thread Fancy Yarns for Testing the Geometrical Model

\begin{tabular}{|c|c|c|c|c|c|c|c|c|}
\hline $\begin{array}{l}\text { Fancy } \\
\text { yarn }\end{array}$ & Effect Threads & Core Threads & binder & $\begin{array}{l}\text { Delivery } \\
\text { speed } \\
\text { m/min }\end{array}$ & $\begin{array}{l}\text { Supply } \\
\text { Speed } \\
\text { m/min }\end{array}$ & \begin{tabular}{|l|} 
Rotational \\
Speed \\
rpm
\end{tabular} & $\begin{array}{l}\text { Overfeeding ratio } \\
\eta \%\end{array}$ & $\begin{array}{l}\text { Theoretical Number of } \\
\text { wraps } \\
\text { wpm }\end{array}$ \\
\hline 1 & Lambswool 120tex/2 & $\begin{array}{l}\text { undyed ply cotton yarn } \\
(\mathrm{R} 144 \mathrm{tex} / 2)\end{array}$ & $\begin{array}{l}\text { Rotor spun } \\
\text { cotton yarn } \\
29.5 \text { tex }\end{array}$ & 30 & 45 & 4500 & 150 & 1 \\
\hline 2 & $\begin{array}{l}\text { Lambswool } \\
83 \text { tex }\end{array}$ & $\begin{array}{l}\text { wool/angora/polyamide } \\
60 \% / 20 \% / 20 \% \\
67 \text { tex }\end{array}$ & \multirow{14}{*}{ 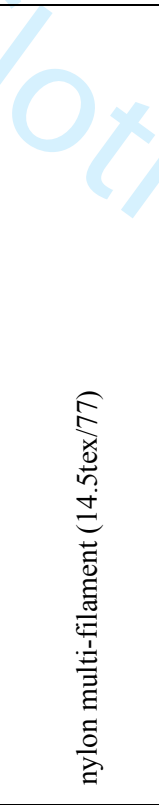 } & 30 & 50 & 8000 & 166 & 266 \\
\hline 3 & $\begin{array}{l}\text { Wool } \\
118 \text { tex/2 }\end{array}$ & $\begin{array}{l}\text { wool/angora/polyamide } \\
60 \% / 20 \% / 20 \% \\
67 \text { tex }\end{array}$ & & 30 & 50 & 7000 & 166 & 233 \\
\hline 4 & Wool 67tex & Cotton 72 tex $/ 3$ & & 30 & 54 & 5700 & 180 & 190 \\
\hline 5 & $\begin{array}{l}\text { Cotton } \\
72 \text { tex } / 3\end{array}$ & Bamboo 24s/3 & & 30 & 51 & 6800 & 170 & 226.7 \\
\hline 6 & Wool 120tex/2 & Natural wool 195 tex/2 & & \multicolumn{5}{|c|}{$\begin{array}{l}\text { Not recorded. This means that the model may apply even though the actual settings of the machine and } \\
\text { the yarn structural parameters are not available. Note that the formulae } 25 \text { and } 26 \text { do not include the } \\
\text { overfeed ratio, while the number of wraps may be readily counted. It was } 32 \text { wrap per decimetre. }\end{array}$} \\
\hline 7 & Acrylic 72 tex $/ 2$ & Acrylic 72 tex $/ 2$ & & 20 & 33 & 3500 & 165 & 175 \\
\hline 8 & Cotton/Bamboo (80/20) 55tex/2 & Combed cotton 72 tex $/ 2$ & & 15 & 24 & 2800 & 160 & 186.7 \\
\hline 9 & Lambswool 83 tex & Cotton/Bamboo (80/20) 55tex/2 & & 14 & 24 & 2800 & 171 & 200 \\
\hline 10 & Bamboo Ne24s/3 & Cotton/Bamboo (80/20) 55tex/2 & & 28 & 48 & 5600 & 171 & 200 \\
\hline 11 & Wool 68tex & Cotton/Bamboo (80/20) 55tex/2 & & 28 & 44 & 5600 & 157 & 200 \\
\hline 12 & Cotton 72 tex $/ 2$ & Cotton/Bamboo (80/20) 55tex/2 & & 28 & 47 & 5700 & 168 & 203 \\
\hline 13 & $\begin{array}{l}\text { wool/angora/polyamide } \\
60 \% / 20 \% / 20 \% \\
67 \text { tex }\end{array}$ & Cotton/Bamboo (80/20) 55tex/2 & & 35 & 46 & 8200 & 131 & 234.3 \\
\hline 14 & Coated wool 72tex/2 & Cotton/Bamboo (80/20) 55tex/2 & & 35 & 40 & 7000 & 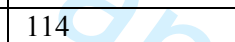 & 200 \\
\hline 15 & Wool 67tex & Coated wool 72tex/2 & & 35 & 45 & 7000 & 129 & 200 \\
\hline
\end{tabular}


Table 2. Experimental testing of the model on a hollow spindle-spinning machine.

\begin{tabular}{|c|c|c|c|c|c|c|c|}
\hline $\begin{array}{c}\text { Fancy } \\
\text { yarn }\end{array}$ & $\begin{array}{c}\text { n } \\
\text { per dm }\end{array}$ & $\begin{array}{c}m \\
\text { per } \mathbf{d m}\end{array}$ & $\begin{array}{c}\text { W } \\
\text { per dm }\end{array}$ & $\begin{array}{c}\mathbf{H}_{2} \\
\mathbf{m m}\end{array}$ & $\begin{array}{c}\mathrm{H}_{1} \\
\mathrm{~mm}\end{array}$ & $\begin{array}{l}\text { Theoretical } \\
\text { value of } L_{e} \\
\text { mm }\end{array}$ & $\begin{array}{c}\text { real value } \\
\text { of } L_{e} \\
\text { mm }\end{array}$ \\
\hline $\begin{array}{l}\text { Fancy } \\
\text { yarn } 1\end{array}$ & 11 & 6 & 17 & 1.10 & 2.66 & 15.3 & 14.5 \\
\hline $\begin{array}{l}\text { Fancy } \\
\text { yarn } 2\end{array}$ & 17 & 11 & 28 & 0.65 & 1.87 & 16.6 & 16.6 \\
\hline $\begin{array}{l}\text { Fancy } \\
\text { yarn } 3\end{array}$ & 24 & 6 & 30 & 0.71 & 2.79 & 17.1 & 16.7 \\
\hline $\begin{array}{l}\text { Fancy } \\
\text { yarn } 4\end{array}$ & 9.5 & 10 & 19.5 & 0.55 & 3.67 & 21 & 18.5 \\
\hline $\begin{array}{l}\text { Fancy } \\
\text { yarn } 5\end{array}$ & 17 & 10 & 27 & 0.62 & 2.48 & 17.9 & 16.7 \\
\hline $\begin{array}{l}\text { Fancy } \\
\text { yarn } 6\end{array}$ & 9 & 23 & 31 & 0.72 & 1.48 & 19.7 & 16.9 \\
\hline $\begin{array}{l}\text { Fancy } \\
\text { yarn } 7\end{array}$ & 10.5 & 9 & 19.5 & 0.97 & 3.73 & 21.0 & 17.1 \\
\hline $\begin{array}{l}\text { Fancy } \\
\text { yarn } 8\end{array}$ & 10.5 & 6 & 16.5 & 0.71 & 3.74 & 16.8 & 15.6 \\
\hline $\begin{array}{l}\text { Fancy } \\
\text { yarn } 9\end{array}$ & 15 & 6 & 21.0 & 0.69 & 3.95 & 18.1 & 16.8 \\
\hline $\begin{array}{c}\text { Fancy } \\
\text { yarn } 10\end{array}$ & 13 & 9 & 22.0 & 0.57 & 3.32 & 19.4 & 16.8 \\
\hline $\begin{array}{c}\text { Fancy } \\
\text { yarn } 11\end{array}$ & 15 & 7 & 22.0 & 0.60 & 4.40 & 20.5 & 1.5 \\
\hline $\begin{array}{c}\text { Fancy } \\
\text { yarn } 12\end{array}$ & 1.2 & 8 & 20.0 & 0.57 & 3.81 & 19.6 & 1.6 \\
\hline $\begin{array}{c}\text { Fancy } \\
\text { yarn } 13\end{array}$ & 22 & 3 & 25.0 & 0.49 & 2.46 & 12.9 & 12.8 \\
\hline $\begin{array}{c}\text { Fancy } \\
\text { yarn } 14\end{array}$ & 20 & 0 & 20.0 & 0.60 & 0.00 & 10.9 & 11.0 \\
\hline $\begin{array}{c}\text { Fancy } \\
\text { yarn } 15\end{array}$ & 18.5 & 3 & 21.5 & 0.61 & 2.27 & 12.6 & 12.9 \\
\hline
\end{tabular}


Table 3. The relationship between the number of wraps and the terms of the model

\begin{tabular}{|c|c|c|}
\hline W (wrap per cm) & $\boldsymbol{\Psi}$ & $\mathcal{F}$ \\
\hline 1 & 5.20 & 10.00126 \\
\hline 2 & 4.71 & 10.0003169 \\
\hline 3 & 4.41 & 10.000001408 \\
\hline 10 & 4.38 & 10.00000316 \\
\hline 20 & 4.23 & \\
\hline
\end{tabular}

\section{List of Figures}

Part I: Sinusoidal

Part II: Helix (Sigmoid)

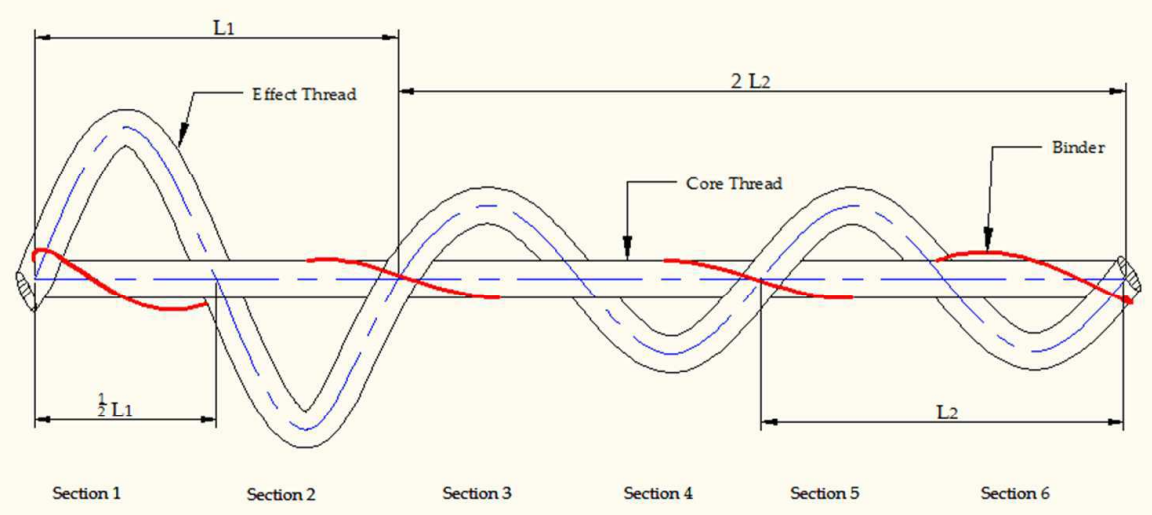

Multi-thread Fancy Yarn Structure

Figure (1) Multi-thread bouclé fancy yarn structure 


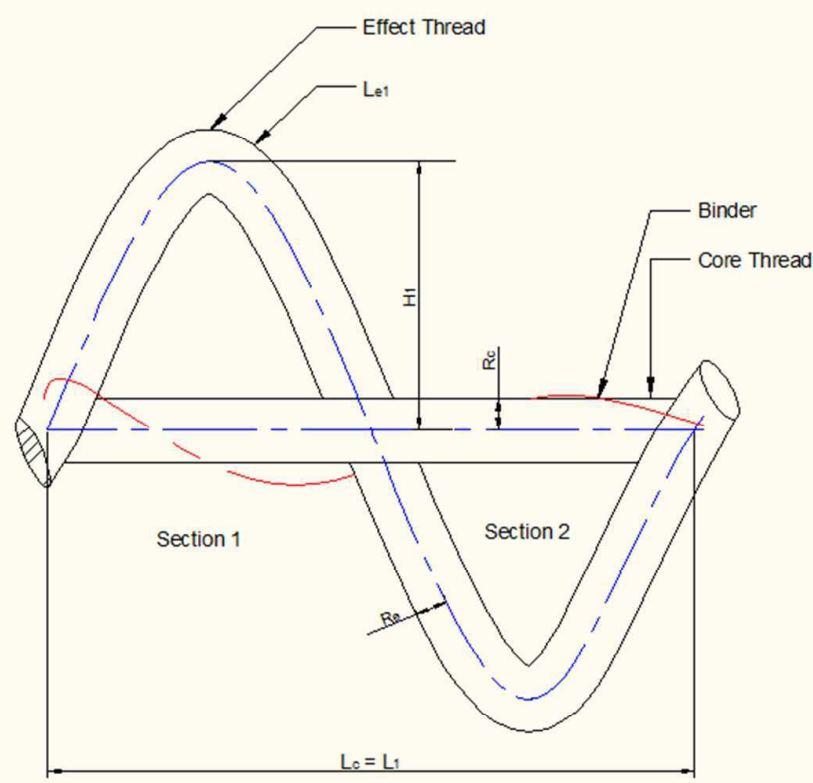

Multi-thread Fancy Yarn Structure: Sinusoidal Part

Figure (2) Sinusoidal part of bouclé yarn structure

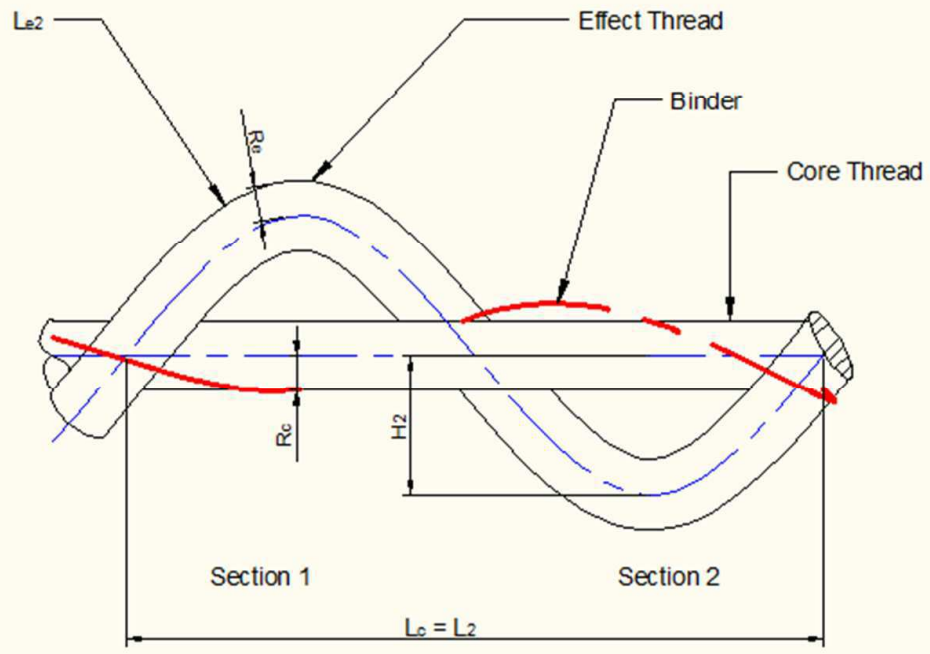

Multi-thread Fancy Yarn Structure: Helical Part (Sigmoid)

Figure (3) Sigmoidal or helical part of bouclé yarn structure 
a

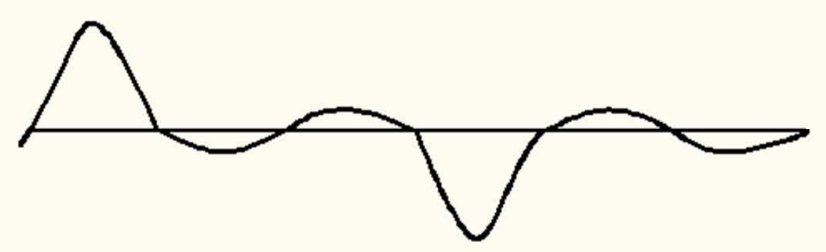

b

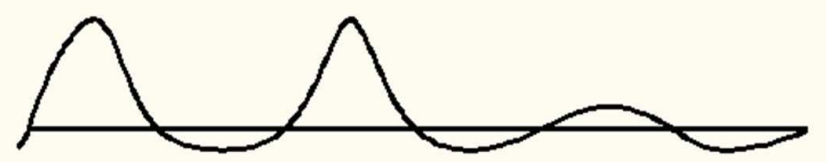

c

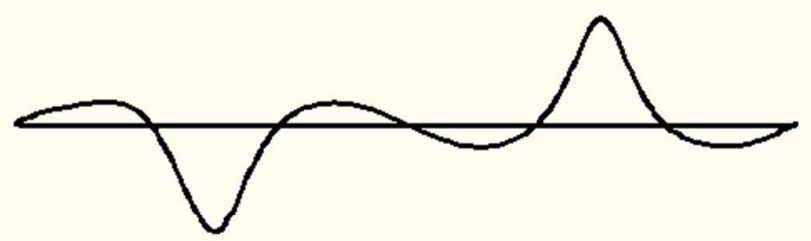

Figure (5) Examples of variants of multi-thread fancy yarn structure 